\title{
Family Wealth Accumulation and Fiscal Prudence among China's Young Adults: Between the Privileged and the Common
}

\author{
Muyan Xie \\ International School, Wuxi Big Bridge Academy, Wuxi, China \\ Email: 1756314803@qq.com
}

How to cite this paper: Xie, M. Y. (2021). Family Wealth Accumulation and Fiscal Prudence among China's Young Adults: Between the Privileged and the Common. Open Journal of Social Sciences, 9, 478-498. https://doi.org/10.4236/jss.2021.99035

Received: August 31, 2021

Accepted: September 19, 2021

Published: September 22, 2021

Copyright $\odot 2021$ by author(s) and Scientific Research Publishing Inc. This work is licensed under the Creative Commons Attribution International License (CC BY 4.0).

http://creativecommons.org/licenses/by/4.0/

\begin{abstract}
Young adults in middle class Chinese families are seeing increased access to their family's wealth. With the growing ubiquity of digital payments and consumer goods, they are spending at an ever increasing rate. But for young adults from less privileged financial backgrounds, high disposable incomes and glamorous shopping items may be out of reach. This paper is designed to analyze the development of financial literacy among all groups of young adults in China and assess the rationality of their financial behavior. I sought to determine the correlations between financial literacy, family income and fiscal prudence. I applied methods like OLS regression, entropy weight model and significance test to establish firm correlations. I hypothesized children of wealthier families would behave in a more financially reasonable way as they tend to have access to more education and general financial information. Thus, I would test using initial hypothesis that more privileged children will react and shop more prudently, which is further proved in the sections below.
\end{abstract}

\section{Keywords}

Financial Literacy, Financial Behavior, Wealth Accumulation, Chinese Young Adults

\section{Introduction}

Booming economies and rapid societal development have raised concern in China for the financial responsibility of the next generation. Some citizens believe par- 
ents and access to information play a large role in determining financial literacy rate of young adults and their spending patterns.

In the research, we are trying to figure out the possible relationship between financial literacy and fiscal prudence, or spending prudence, among Chinese young adults. By doing so, we can better understand the usefulness of financial education in guiding young adults' behaviors and pave way for future buildup of the problem.

\section{Literature Review}

Throughout the researches area, the most related paper to our topic here should the paper Financial Prudence among Young (Pillai, Carlo, \& D'souza, 2012), in which they discussed about financial prudence of the youth through second hand data and pure theoretical assumptions.

This paper is going to significantly build upon that one by utilizing quantifiable indices and use precise and statistically significant samples.

In New Adolescent Money Attitude Scales: Entitlement and Conscientiousness (Beutler \& Gudmunson, 2012), the authors tried to provide the spending behaviors of the young with psychological reasons, including theory of planned behaviors.

Also, previous studies have tried to figure out gender differences in the financial literacy rates and the gender differences in its effectiveness in influencing the youth's prudence (Sharif, 2020). In this paper, we are going to pool the two genders together for the fact that the respondents to the questionnaire are halved through gender and sex is not a major concern here if we are designing to link spending behaviors with financial literacy rates.

Here I will try to take that into account in explaining my own results too.

\section{Data}

\subsection{Collection}

Several measures were taken to avoid selection bias in the survey results. As we assume young adults from less wealthy families have less access to online polls, I fixed the number of respondents in each income group. Moreover, the survey was launched to the public during the Chinese Spring Festival, 2021, at which time most young adults are relatively free and willing to respond. We finally collected 137 samples from targets whose self-reported family income is less than 50,000 yuan per year and 372 samples from families above that threshold.

The questionnaire was carefully worded to avoid response bias. We formatted the questionnaire as shown in the appendix, which tried to eliminate bias and quantify the metrics.

The survey was conducted both online and offline. Leveraging my access to my fellow students, I first distributed the survey to my club members in School Economics Club. I then launched the questionnaire to the Internet and received hundreds of responses. 


\subsection{Exploration}

After collecting the results, I tried to quantify all the responses. Questions 1 and 10 focus the respondent's family income overview and should be treated as basic demographic information. Questions 2 to 6 test the respondent's level of financial literacy. Questions 7 to 9 are designed to assess the prudence of the respondent's financial behaviors.

As we can categorize the questions into 3 types, I generate three separate indices named $F L R, F B R$ and $F W A L$, representing for Financial Literacy Rate, Financial Behavior Rationality and Family Wealth Accumulation Level.

In the sensitivity analysis, we will directly put the raw data of all the question answers in the Financial Literacy assessment areas into the model as independent variables to eliminate the error that can be generated during the entropy weight defined procedure.

\section{Statistical Models}

\section{Survey Responses Indices}

As we may discern from the questionnaire attached in the appendix, the questions have defined correct answers and defined indicator of goodness ${ }^{1}$.

We then define the variables $F L R, F B R$, and $F W A L$ based on these questions. $F L R$ is more like a test score. Based on the correctness of the answers to the Financial Literacy questions, we can define them as a quiz. In order to ensure to eliminate the luck part (those who choose by random and get the question right), I add in the following algorithm as shown in Equation (1):

$$
S_{e}=0=\frac{1}{I} \times W+\frac{I-1}{I} \times D
$$

$S_{e}$ stands for the expected score of a single question if the respondent simply guesses it. $I$ stands for the number of items for selection in the question. $W$ stands for the score awarded for a correct answer. $D$ stands for the score awarded for an incorrect answer.

Here we set the winning points to be $4 . I$ is question specific, indicating that $D$ is also specific to the question. For example, question 3 has three items to be chosen and only one correct answer. 4 points are won for a correct answer and 2 are deducted for an incorrect answer. Thus, the expected score is 0 .

Therefore, we can discern that those who only guess all the questions will get an expected score of 0 .

We should also consider the difficulty of each question. It is thus reasonable that we should use the Entropy Weight Model, as going to be explained in the next subsection.

Then we need to determine the value of $F B R$ for each sample. $F B R$ is defined as the rationality of the financial behavior of the respondent. Questions 7 to 9 account for the assessment of this variable. These questions has unlimited num-

${ }^{1}$ This means that as the responses' numerical values go down or up, it is clear whether the responses are good or bad, within a general trend. 
ber of possible answers and are defined all as Minimal Indicators ${ }^{2}$. Because we want to see an index in traditional sense, we process each response in for FBR as shown in Equation (2):

$$
x_{j}^{\prime}=M_{j}-x_{j}
$$

And we will define $M_{j}$ in Equation (3):

$$
M_{j}=\max _{1 \leq i \leq n}\left\{a_{i j}\right\}
$$

where $M_{j}$ is simply the largest value in the column.

After the process, we can discern that smaller the original value is, the larger the final value will be, satisfying to our requirement.

We can see that due to the fact that all the responses are of different dimensions and magnitudes, we need to eliminate these impacts. We then will conduct the normalization for the indicators of $F B R$, as shown in Equation (4).

$$
a_{i j}^{*}=\frac{a_{i j}}{\sqrt{\sum_{i=1}^{n} a_{i j}^{2}}}(i=1,2, \cdots, n, 1 \leq j \leq m)
$$

After these processes, the variables can be changed from minimal indicators to larger indicators and then to indicators of equatable magnitude.

Next, we will again use Entropy Weight Model in order to settle down the weight of each factor to minimize the importance of the less varied determinants while magnify the importance of the more varied ones.

As for $F W A L$, we will define it as a row matrix with two columns. The first column will contain a value of 0 or 1.0 indicates that the respondent's family earn an income less than 50,000 RMB per year and should be classified in the less privileged group, as indicated by the Chinese Communist Party's 5 Years' Targets. 1 means that the income is more than 50,000 RMB annually and should be treated as wealthy. The second value is the percentage income increase of the family, being treated as the wealth accumulation increasing rate of the family. For a better illustration we will use the following Differential Equations, where $W$ stands for the wealth occupied by the family:

$$
V_{n}=\frac{\mathrm{d} W}{\mathrm{~d} t}, A r=\frac{\mathrm{d} W}{\mathrm{~d} t}-2 \%
$$

We define $V_{n}$ as the nominal increasing rate of wealth. The accumulation rate $A r$, on the other hand, should be defined as the increase in purchasing power over time, equaling $V_{n}$-CPI of the country. We will set the CPI for China as $2 \%$.

In one word, for $F W A L$, the first column indicates which group, $G_{c}$ or $G_{p}$, the respondent should be in with $G_{c}$ refers to a common family while $G_{p}$ refers to a wealthy family as defined by annual income.

\section{Entropy Weight Model}

Entropy characterizes the level of disorder and, to a large extent, the amount of information in a given system. In this case, the more randomness a variable displays, the higher its entropy and the faster its entropy increases, and so grows ${ }^{2}$ This means that as the responses going smaller and smaller, the better the response is. 
the amount of information we can extract from this variable.

The entropy weight method uses this principle to calculate weighting for different variables based on the entropy of their distributions. A larger variance or entropy generally means a larger weight. In the extreme case, if all values for a index are identical, then it does not matter what the value is, and we should give it zero weight.

\section{TOPSIS Analysis}

After getting all the needed indicator values for $F L R$ and $F B R$, we can use the TOPSIS method to comprehensively evaluate each sample get their relative wellness.

We can get the best response group combination and the worst group combination, and evaluate using Kendall's tau distance model (Jahanshahloo, Lotfi, \& Izadikhah, 2006):

$$
\begin{aligned}
& D_{i}^{+}=\sqrt{\sum_{j=1}^{m} w_{j}\left(Z_{j}^{+}-Z_{i j}\right)^{2}} \\
& D_{i}^{-}=\sqrt{\sum_{j=1}^{m} w_{j}\left(Z_{j}^{-}-Z_{i j}\right)^{2}}
\end{aligned}
$$

We can thus use the final evaluation equation:

$$
C_{i}=\frac{D_{i}^{-}}{D_{i}^{+}+D_{i}^{-}}
$$

The return value should be a value between 0 and 1 .

\section{Ordinary Least Square Regression Model}

After obtaining the desired values for analysis, we sought out to determine correlation between one or more independent variables and one dependent variable. For convenience and other concerns defined $F L R$, we can simply use the two variable Ordinary Least Square Regression Model for FLR and FBR.

Now we will articulate our formulas for this model.

First, the general formula for OLS is shown in Equation (8):

$$
y_{i}=\beta_{1} x_{i 1}+\beta_{2} x_{i 2}+\cdots+\beta_{p} x_{i p}+\varepsilon_{i}
$$

where $y_{i}$ is the response variable; $\beta$ are the unknown variables; $x_{i}$ are the independent variables and $\varepsilon_{i}$ is the unobserved error.

\section{Significance Test Model}

Next we should concentrate on the comparison between two income groups, $G_{c}$ and $G_{p}$.

The two samples' indices are FLR and FBR. To compare the two groups of pair values, we can simply use the Two Sample T-test.

To begin with, we will check whether each group satisfies the requirement for analysis using this method.

The samples can be treated as random for all respondents as the questionnaires are randomly selected. The sample is done without replacement. Luckily we should assume the sample size is far less than $10 \%$ of the whole population. Also the sample sizes are bigger than 30 for both samples. We thus satisfy the random and normal requirements. 
As the true standard deviation of both income groups for FLR and FBR is unknown, we can use the sample standard error as a close approximation.

\section{Model Results}

We can compile all the calculated information for the entropy weight model into Figure 1 and Figure 2.

After getting the weights, we are able to use TOPSIS Method to evaluate. For brevity, the final results are available in the appendix. We display some examples of the values as classified by $G_{c}$ and $G_{p}$ in Figure 3.

Then we came to our OLS Regression Model. The model produced the following parameters, as shown in Table 1.

From the outcomes we can see that the regression model can only explain $14.72 \%$ of the observed values. However, the model is still functional because the F test shows that $F=87.524$ with $p=0.000<0.05$, meaning that $F L R$ definitely will affect $F B R$ values.

The interpreted formula can be expressed as:

$$
F \hat{B} R=0.84-0.296 F L R
$$

indicating a negative and significant relationship between the two variables, contradicting our assumption that as FLR increases, FBR will increase.

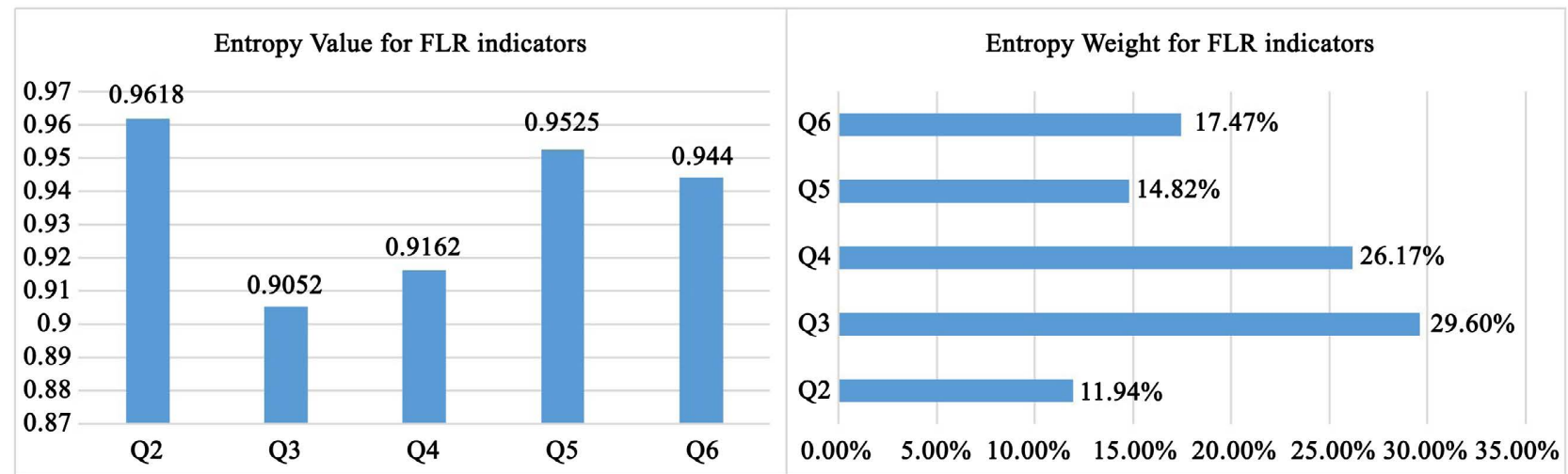

Figure 1. Entropy results for FLR.

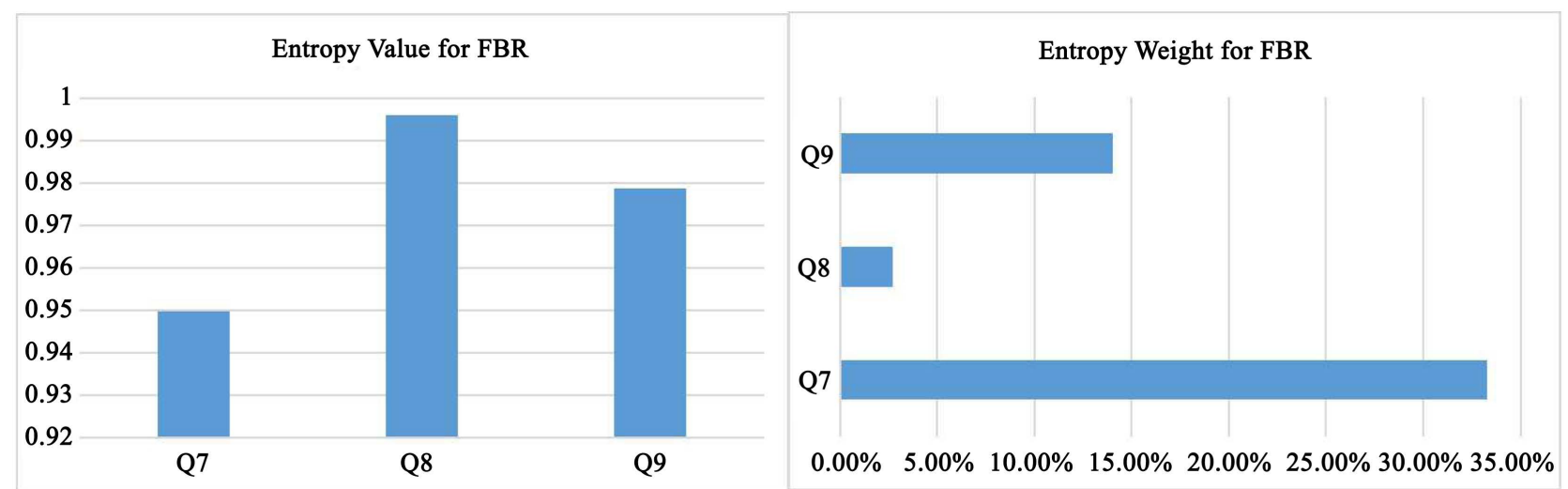

Figure 2. Entropy results for FBR. 


\begin{tabular}{|c|c|c||c|c|c|}
\hline \multicolumn{7}{|c|}{ Group Common Report } \\
\hline Sample & FLR & FBR & Sample & FLR & FBR \\
\hline 1 & 0.656 & 0.842 & 16 & 0.493 & 0.785 \\
\hline 2 & 0.645 & 0.88 & 17 & 0 & 0.944 \\
\hline 3 & 0.269 & 0.89 & 18 & 0.253 & 0.928 \\
\hline 4 & 0.269 & 0.944 & 19 & 0.344 & 0.875 \\
\hline 5 & 0.269 & 0.88 & 20 & 0.427 & 0.956 \\
\hline 6 & 0.435 & 0.875 & 21 & 0.515 & 0.628 \\
\hline 7 & 0.731 & 1 & 22 & 0.515 & 0.928 \\
\hline 8 & 0.269 & 0.875 & 23 & 0.355 & 0.928 \\
\hline 9 & 0 & 0.865 & 24 & 0.632 & 0.956 \\
\hline 10 & 0.656 & 0.928 & 25 & 0.427 & 0.89 \\
\hline 11 & 0.269 & 0.944 & 26 & 0.573 & 0.88 \\
\hline 12 & 0.737 & 1 & 27 & 0.656 & 0.754 \\
\hline 13 & 0.545 & 0.88 & 28 & 0 & 0.561 \\
\hline 14 & 0.368 & 0.88 & 29 & 0.515 & 0.865 \\
\hline 15 & 0.269 & 0.89 & 30 & 0.253 & 0.944 \\
\hline
\end{tabular}

\begin{tabular}{|c|c|c||c|c|c|}
\hline \multicolumn{5}{|c|}{ Group Previleged Report } \\
\hline Sample & FLR & FBR & Sample & FLR & FBR \\
\hline 138 & 1 & 0.51 & 153 & 1 & 0.408 \\
\hline 139 & 0.731 & 0.45 & 154 & 1 & 0.488 \\
\hline 140 & 0.565 & 0.563 & 155 & 1 & 0.611 \\
\hline 141 & 0.545 & 0.59 & 156 & 0.565 & 0.324 \\
\hline 142 & 1 & 0.563 & 157 & 0.573 & 0.563 \\
\hline 143 & 0.485 & 0.674 & 158 & 0.632 & 0.475 \\
\hline 144 & 0.632 & 0.776 & 159 & 0.731 & 0.728 \\
\hline 145 & 4 & 0.401 & 160 & 1 & 0.466 \\
\hline 146 & 0.493 & 0.638 & 161 & 0.568 & 0.538 \\
\hline 147 & 0.747 & 0.331 & 162 & 1 & 0.403 \\
\hline 148 & 0.545 & 0.499 & 163 & 0.632 & 0.604 \\
\hline 149 & 1 & 0.373 & 164 & 0.545 & 0.654 \\
\hline 150 & 0.493 & 0.59 & 165 & 1 & 0.674 \\
\hline 151 & 0.731 & 0.564 & 166 & 0.632 & 0.663 \\
\hline 152 & 0.737 & 0.403 & 167 & 0.545 & 0.364 \\
\hline
\end{tabular}

Figure 3. Entropy results for FBR.

Table 1. OLS regression results.

\begin{tabular}{cccccccc}
\hline Items & Coef & $\begin{array}{c}\text { Std. } \\
\text { Err }\end{array}$ & $t$ & $p$ & $R^{2}$ & $\begin{array}{c}\text { Adjusted } \\
R^{2}\end{array}$ & $\mathrm{~F}$ \\
\hline Constant & 0.84 & 0.02 & 41.811 & $0.000^{* *}$ & 0.147 & 0.146 & $\begin{array}{c}\mathrm{F}(1,507)=106.246, \\
p=0.000\end{array}$ \\
& & & & & & & $\begin{array}{c}\text { F }(1,507)=106.246, \\
p=0.000\end{array}$ \\
\hline
\end{tabular}

The $p$-value for the variable coefficient is 0.000 , which is within a significance level as strict as 0.01 , demonstrating that the negative correlation is almost certain.

Next, we will first compare the sample distribution in $G_{c}$ and $G_{p}$.

We will use the two sample T-test for significance. The results are in Table 2.

Also we tested FBR in Table 3.

\section{Sensitivity Analysis I}

Wary of the low $R^{2}$ value for the OLS regression model, I decided to do a sensitivity analysis on it. This procedure includes testing the accountability of $F B R$ on each respondent without the intermediate calculation of FLR.

The model shows the following results in Figure 4.

With these adjustments, $R^{2}$ is now higher and still shows an indication of correlation in terms of the $\mathrm{F}$ score.

\section{Extension}

\subsection{Reflection}

\subsubsection{Results Deviation and Conformation}

Deviation: The model results deviate from our expectations. We cannot confirm that: 
OLS Regression Results ( $n=509$ )

\begin{tabular}{cccccccc}
\hline & Coef & Std. Err & $t$ & $p$ & $R^{2}$ & Adj $R^{2}$ & $F$ \\
\hline Const. & 0.786 & 0.012 & 65.042 & $0.000 * *$ & & \\
Q2 & -0.01 & 0.002 & -4.105 & $0.000 * *$ & & & $F$ \\
Q3 & -0.008 & 0.002 & -3.275 & $0.001 * *$ & & 0.26 & 0.253 \\
Q4 & -0.007 & 0.003 & -2.501 & $0.012 *$ & & & $(5,503)=41.620, p=0.000$ \\
Q5 & -0.022 & 0.003 & -6.915 & $0.000 * *$ & & & \\
Q6 & -0.012 & 0.003 & -3.564 & $0.000 * *$ & & & \\
\hline
\end{tabular}

Depedent Variable: FBR

D-W Value: 1.608

$* p<0.05 * * p<0.01$

Figure 4. OLS model output.

Table 2. T-test result for FLR in two groups.

\begin{tabular}{ccc}
\hline$t$ & $p$-value & Df \\
\hline-14.4079 & 0.000 & 294.778 \\
\hline
\end{tabular}

Table 3. T-test result for FBR in two groups.

\begin{tabular}{ccc}
\hline$t$ & $p$-value & Df \\
\hline 25.5381 & 0.000 & 278.564 \\
\hline
\end{tabular}

1) Young Adults living in privileged wealthy families will conduct more rationally in financial behaviors than the young from the common backgrounds.

2) Financial Literacy Rate will necessarily increase rationality of financial behaviors.

Conformation: However, one of the t-tests confirms the following hypothesis:

1) Young Adults living in privileged wealthy families have higher financial literacy rate than those in the common families.

We can aggregate the findings in one chart as in Figure 5.

The difference between the two groups' two indices is clear.

Suspect: Some people may suggest that the wealth accumulation rate, $A r$, will decrease the financial prudence of young adults. For responsibility, I will picture both variables in Figure 6.

Verification: For clarity, we will show the results of the tests only:

From this chart we can discern that $A r$, the J in the chart, has no defined relationship with $F B R$.

\subsubsection{Lurking Variables}

Of common sense, increasing financial literacy will definitely increase one's financial rationality. This leads us to wonder about the existence of lurking variables in this research.

We cannot conduct a controlled experiment in this area. Thus the most reasonable statistical account may be the following variables: 


\section{Two group in one Chart}

1.2

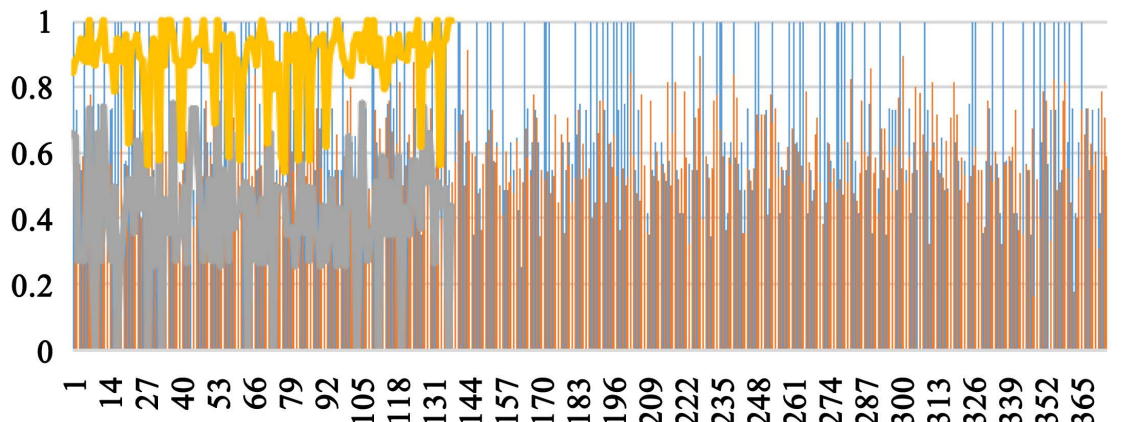

FLRP FBRP $=$ FLRC $=$ FBRC

Figure 5. Group overall results.

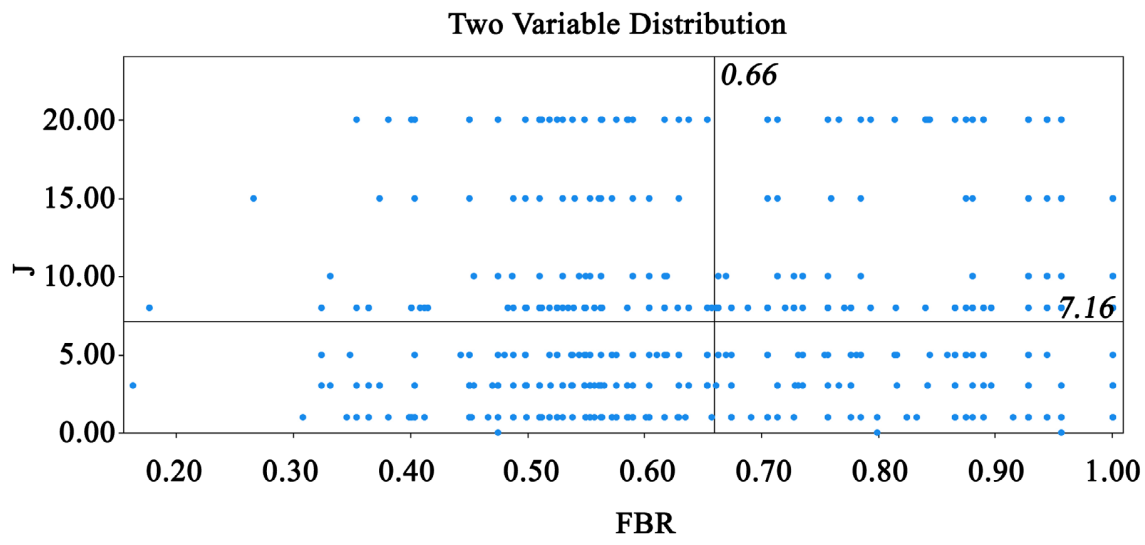

Figure 6. Two variable distributions.

1) Households that can provide decent financial literacy education environment will have more stimuli to urge the young to conduct irrational purchases.

2) Parents in lower income households may offer less financial support for their children, thus prohibiting them from making financially irresponsible purchases.

It is a pity, but we cannot get conduct a controlled experiment due to time, financial and moral restrictions.

\subsection{Psychological Explanation}

Even though statistically we are almost done here, we can still account for the observed data using behavior finance and Gestalt Psychology.

\subsubsection{Marginal Utility Theory}

Excessive spending does not necessarily imply irrationality on the part of the consumer. Instead, we may consider that the consumer is rather buying "unnecessary" items in pursuit of a sense of fulfillment. In this sense, it is rightful that we should introduce the Marginal Utility Theory in Microeconomics. According 
to Marginal utility theory, "Utility is an idea that people get a certain level of satisfaction/happiness/utility from consuming goods and service" and "Marginal utility is the benefit of consuming an extra unit".

Thus we can propose our theory:

- Marginal Utility Per Dollar for children of upper income households is less than for those of the middle and lower class backgrounds.

- To achieve the same amount of utility, young adults of wealthy households will purchase more.

- Necessary purchases for an individual have an identical dollar value regardless of his or her financial background.

- And thus the privileged young will purchase more "unnecessary" goods.

Still, unfortunately, it is only our postulation and cannot be verified using substantial statistics. However, the following suppositions can have some kind of supporting evidence.

\subsubsection{Access to Confusing Purchasing Chances}

Another factor we must consider is the effect of easy purchases and confusing advertisements.

We will set the following variables to quantify our assumption. Let $T_{i}$ be the temptation coefficient of the product. $P_{i}$ represents the probability of getting confused and buying the product, which depends on both $F L R$ and $T_{i}$.

To simplify the model, we set three temptations of different degrees, being mild temptation, intermediate temptation and high temptation respectively. The consumer passes through these temptations daily, as demonstrated in Figure 7.

We set here that N1, N2, N3 should be 3, 2 and 1 respectively for young adults in wealthy families and will be 2,1 and 0 for young adults in the less privileged families for their lack of access to such temptations in their living environment.

We are able to measure the effect of the differences in temptation coefficient for products and the number of temptations in the following simulations 7.3.

\subsubsection{Theory of Planned Behaviors}

By the concept of TPB, current behaviors are determined by past experiences and interactions. The young adults might base their purchasing behaviors on observed behavior of their parents. We could investigate the purchasing behavior of various parents and observe whether or not that correlates with the observed behavior of their children. Unfortunately, this research will have to be left to further surveys (Icek Ajzen, 2011).

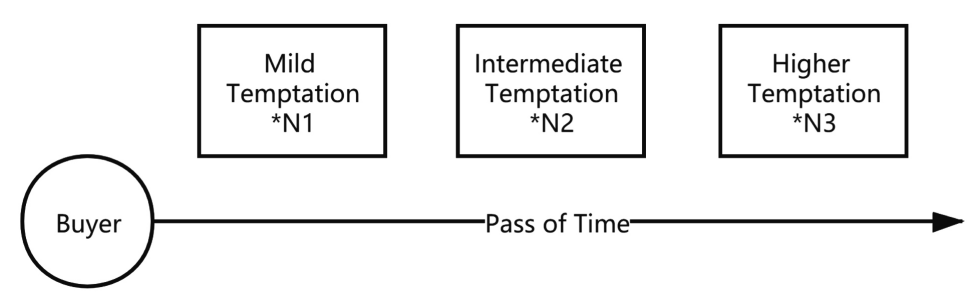

Figure 7. Flow chart of temptations. 


\subsection{Statistical Simulation}

\section{Monte Carlo Simulation}

Monte Carlo simulation is actually a general reference to an idea. As long as a large number of random samples are used when solving a problem, and then probabilistic analysis is performed on these samples, the method of predicting the results can be called a Monte Carlo method.

The idea for this model is that we will conduct numerous trials to simulate the process of living for the two groups and determine the average rate of purchasing unnecessary items.

\section{Markov Chain Simulation}

In the real world, there are many such phenomena: Under the condition that a certain system has known the current situation, the future state of the system is only related to the present, and the past history is not directly related. The mathematical model describing this kind of random phenomenon is called the Markov model.

In this situation, we will set an additional intermediate calculation in the program. This intermediate is affected by the former purchase of the day and will lower the probability of being lured by the same kind or higher level or temptation. An illustration is given below in Figure 8 .

The equation form of the Markov Chain Model is:

$$
P\left\{\xi_{n+1}=j \mid \xi_{n}=i, \xi_{n-1}=i_{n-1}, \cdots, \xi_{1}=i_{1}\right\}=P\left\{\xi_{n+1}=j \mid \xi_{n}=i\right\}
$$

For clarity, the coding will be available in the appendix and the next section will present the model results directly.

\subsection{Models Results}

Table 4 is the summary of a simulations run for 1,000,000 iterations. ${ }^{3}$ :

We can see our models do confirm that advertisements and easy access to payment is a factor in affecting $F B R$.

\subsection{Additional Researches}

To completely utilize my data, I conducted the following procedure. For brevity, I will present the statistical methods and results only briefly.

Population Estimation: Using a 99\% confidence interval, we can state that we are we are $99 \%$ sure that the true population value for $F L R$ and $F B R$ will be contained by Table 5 .

Differences with Confidence: $99 \%$ confidence intervals for the difference of the means of the indicators of both groups can be expressed, as shown in Table 6 .

Table 4. Monte carlo results.

\begin{tabular}{ccc}
\hline Stat. & $G_{c}$ Irrational Rate & $G_{p}$ Irrational Rate \\
\hline Mean & $14.57 / 100$ & $9.87 / 100$ \\
Variation & $0.78 / 100$ & $0.98 / 100$ \\
\hline
\end{tabular}

${ }^{3}$ We automatically use the FLR acquired in the survey as parameters in the program; Temptation rates are set different for two groups, being 3:2:1 and 2:1:0 respectively. Other factors are set equal. 


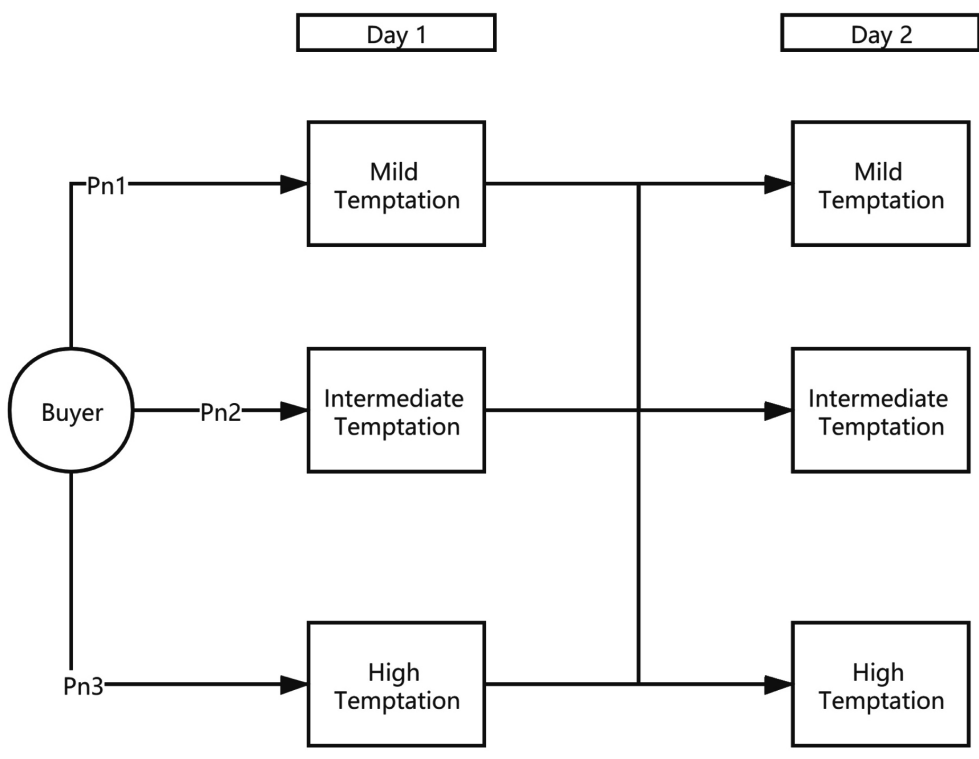

Figure 8. Flow chart of TPB.

Table 5. Population estimation.

\begin{tabular}{cccc}
\hline group & $99 \%$ Confidence Interval & $\mathrm{ME}$ & $\mathrm{n}$ \\
\hline Overall FLR & $(0.581495,0.636505)$ & 0.027505 & 509 \\
Overall FBR & $(0.637684,0.680316)$ & 0.021316 & 509 \\
$G_{c} F L R$ & $(0.369271,0.448729)$ & 0.039729 & 137 \\
$G_{c} F B R$ & $(0.855555,0.906445)$ & 0.025445 & 137 \\
$G_{P} F L R$ & $(0.652735,0.711265)$ & 0.029265 & 372 \\
$G_{P} F B R$ & $(0.55928,0.59472)$ & 0.01772 & 372 \\
\hline
\end{tabular}

Table 6. CI estimation.

\begin{tabular}{ccc}
\hline Name & $99 \%$ Confidence Interval & ME \\
\hline$G_{c} F L R-G_{p} F L R$ & $(-0.338868,-0.241132)$ & 0.048868 \\
$G_{c} F B R-G_{p} F B R$ & $(0.288845,0.331155)$ & 0.021155 \\
\hline
\end{tabular}

\subsection{Sensitivity Analysis II}

We will vary the temptation rates in the simulation in order to test the sensitivity and significance of the tests.

Trail one: $G_{p} 3: 3: 3 G_{c} 2: 2: 1$,

Trial two: $G_{p}$ 3:3:2 $G_{c}$ 2:2:2.

The results show the same pattern as that in the previous tests, making $F B R$ indicators lower for $G_{p}$ than $G_{c}$.

\section{Suggestions}

No matter what the reason is, young adults from higher income households demonstrate more "irrational" shopping behavior. From the results of our statistical 
simulation, we can suspect that if we can change some of the variables in the test, the results can be improved. Sensitivity Analysis II was highly suggestive of our original hypotheses.

From these, we can propose the following suggestions to fight the observed lack of fiscal prudence of China's young adults:

- Scrutinize advertisements,

- Offer more financial education to further increase the Financial Literacy Rate,

- Limit young adults' access to online payment methods.

\section{Conclusion}

This article contains a plethora of statistical analyses. For brevity, lots of obscured and unnecessary procedures have been eliminated. However, to summarize the findings, we have included this chapter.

\subsection{Outcomes}

First of all, from the OLS and F test, we can see that the correlation between FLR and $F B R$ is weak and possibly even unexpectedly negative.

Furthermore, young adults from less affluent households demonstrate an increased scrutiny of nonessential purchases when compared to their wealthier counterparts, as indicated in the significance test.

Finally, young adults from wealthier background have higher financial literacy rates than those from less privileged ones.

\subsection{Suggestions}

Some of our proposals for the cause of the unexpected results are not fit for implementation or need a further independent research to confirm. However, using statistical simulation methods, we have confirmed that advertisements and easy access to payment methods do increase a young adult's theoretical likelihood of buying irresponsibly.

We thus propose that advertising should be further controlled to limit its sensational effects and that parents should limit their children's access to mobile payments methods like Alipay in China.

Finally, we can see that financial literacy rate still plays a large role in determining the prudence of an individual's spending behavior. For this reason, we as a society should continue to increase the availability of and access to financial education for all adults in China.

\section{Special Thanks}

This article is inspired by my Counselors, Erte Li at Wuxi Big Bridge Academy. He gave me phenomenal ideas and corresponding action guidelines. This paper could not have been realized without his help.

Thanks to those who responded to the questionnaires. It's you who help to understand the financial behaviors now in China. 


\section{Acknowledgements}

The survey that provided the data for analysis was conducted by an investigation group lead by the author, Muyan Xie, at Wuxi Big Bridge Academy International School Economics Club. As the president of the club, Muyan Xie leads his team to disseminate the survey. This paper was written solely by Muyan Xie.

\section{Conflicts of Interest}

The author declares no conflicts of interest regarding the publication of this paper.

\section{References}

Ajzen, I. (2011). The Theory of Planned Behaviour: Reactions and Reflections. Psychology \& Health, 26, 1113-1127. https://doi.org/10.1080/08870446.2011.613995

Beutler, I. F., \& Gudmunson, C. G. (2012). New Adolescent Money Attitude Scales: Entitlement and Conscientiousness. Journal of Financial Counseling and Planning, 23, 14. https://search.ebscohost.com/login.aspx?direct=true\&db=psyh\&AN=2013-08936-002\& $\underline{\text { site }=\text { ehost-live\&scope }=\text { site }}$

Jahanshahloo, G. R., Lotfi, F. H., \& Izadikhah, M. (2006). An Algorithmic Method to Extend TOPSIS for Decision-Making Problems with Interval Data. Applied Mathematics and Computation, 175, 1375-1384. https://doi.org/10.1016/j.amc.2005.08.048

Pillai, K. R., Carlo, R., \& D'souza, R. (2012). Financial Prudence among Youth. Journal of Contemporary Management Research, 6, 52-68.

https://search.ebscohost.com/login.aspx?direct=true\&db=bth\&AN=90299646\&site=eh ost-live\&scope $=$ site

Sharif, S. P. et al. (2020). Gender Differences in Financial Literacy and Financial Behaviour among Young Adults: The Role of Parents and Information Seeking. Journal of Family and Economic Issues, 41, 672-690.

https://doi.org/10.1007/s10834-020-09674-Z 


\section{Appendices}

\section{Questionnaire}

本问卷针对是中国户籍的13到20岁青年。

This survey is targeted toward young adults between 13 to 20 years old with Chinese Passport.

- 我满足条件参加啦!

Yes, I am qualified!

- 我好像不能参加诶。

Sorry, but I am not qualified.

1. 请问您的家庭年收入为多少人民币? 本问卷不记名, 请放心作答。

What is your family yearly income in yuan? This questionnaire is anonymous, please feel free to answer.

- 0 - 50000

- $50000+$

以下为一个小测验, 请作答

Below is a small quiz, please help us answer it.

2. 请问投资银行和商业银行是一样的嘛?

Is investment bank the same as commercial banks?

- 是的

Yes

- 不是的

No

3. 请问下面哪个最接近中国的银行的不定期存款利率?

Which of rate is the closest to interest rate of deposits in Chinese banks?

- $0.3 \%$ 每年

$0.3 \%$ per year

- $5 \%$ 每年

$5 \%$ per year

- $8 \%$ 每年

$8 \%$ per year

4. 请问降准指的是什么?

What does lowering reserve requirement means?

- 调低中央银行的资金储备量

Lowering Central Bank's amount of preparation reserve

- 调低所有银行的资金储备率

Lowering all banks' rate of preparation reserve

- 调低所有银行的准备利润率

Lowering all banks' rate of preparation interest

- 调低所有证券交易所得开会金额要求

Lowering all stock exchanges' account setup capital requirement

5. 请问以下哪个组合中两个物品的价格走势会大概率相反?

Which of the following pairs will have the two items' price developing at an opposite direction?

- 黄金和股市

Gold and Stocks

- 黄金和石油

Gold and Oil

- 房价和股市

Houses and Stocks

6. 请问Beta（在股市中）指的是什么?

What does Beta stands for in stock markets?

- 风险

Risk

- 相对价格

Relative Price

・股票回本时间

Time needed for a stock to earn its original value 
- 账户的同向方差

Covariance of a portfolio

7. 请问您在非生活必须品方面的消费频率为什么? 金额大概为多少?

What is your frequency of shopping not must-needed items? How much do they sum up?

- ( ) 次/每天

( ) times/per day

- ( ) $\mathrm{RMB} /$ 每天

( ) RMB/per day

8. 请问您消费后后悔的频率为多少?

What is your frequency of regretting the shopping you made?

- () 次/每20次

()times/per 20 times

9. 请问您的后悔的消费的金额大概为多少呢?

What is the amount of the shopping that you regret?

- ( ) $\mathrm{RMB} /$ 每年

( ) $\mathrm{RMB} /$ per year

10. 您的家庭的收入在过去三年中提高了多少呢?

On what percentage did your family's income increase in the past three years?

- ( )\%

\section{Survey Data Chart}

\section{$G_{c}$ Results}

\begin{tabular}{|c|c|c|}
\hline Sample & FLR & FBR \\
\hline 1 & 0.656 & 0.842 \\
\hline 2 & 0.645 & 0.88 \\
\hline 3 & 0.269 & 0.89 \\
\hline 4 & 0.269 & 0.944 \\
\hline 5 & 0.269 & 0.88 \\
\hline 6 & 0.435 & 0.875 \\
\hline 7 & 0.731 & 1 \\
\hline 8 & 0.269 & 0.875 \\
\hline 9 & 0 & 0.865 \\
\hline 10 & 0.656 & 0.928 \\
\hline 11 & 0.269 & 0.944 \\
\hline 12 & 0.737 & 1 \\
\hline 13 & 0.545 & 0.88 \\
\hline 14 & 0.368 & 0.88 \\
\hline 15 & 0.269 & 0.89 \\
\hline 16 & 0.493 & 0.785 \\
\hline 17 & 0 & 0.944 \\
\hline 18 & 0.253 & 0.928 \\
\hline 19 & 0.344 & 0.875 \\
\hline 20 & 0.427 & 0.956 \\
\hline 21 & 0.515 & 0.628 \\
\hline 22 & 0.515 & 0.928 \\
\hline 23 & 0.355 & 0.928 \\
\hline 24 & 0.632 & 0.956 \\
\hline 25 & 0.427 & 0.89 \\
\hline 26 & 0.573 & 0.88 \\
\hline 27 & 0.656 & 0.754 \\
\hline 28 & 0 & 0.561 \\
\hline 29 & 0.515 & 0.865 \\
\hline 30 & 0.253 & 0.944 \\
\hline 31 & 0.263 & 0.928 \\
\hline 32 & 0.568 & 0.576 \\
\hline 33 & 0 & 1 \\
\hline 34 & 0.455 & 0.865 \\
\hline 35 & 0.355 & 1 \\
\hline 36 & 0.355 & 1 \\
\hline 37 & 0.747 & 0.956 \\
\hline 38 & 0.269 & 0.88 \\
\hline 39 & 0.344 & 0.875 \\
\hline 40 & 0.368 & 0.576 \\
\hline 41 & 0.493 & 0.88 \\
\hline 42 & 0.263 & 1 \\
\hline 43 & 0.565 & 0.865 \\
\hline 44 & 0.731 & 0.875 \\
\hline 45 & 0.731 & 0.928 \\
\hline 46 & 0.565 & 0.944 \\
\hline & & \\
\hline
\end{tabular}

\begin{tabular}{|c|c|c|}
\hline Sample & FLR & FBR \\
\hline 47 & 0.427 & 0.928 \\
\hline 48 & 0.269 & 1 \\
\hline 49 & 0.368 & 0.88 \\
\hline 50 & 0.515 & 0.89 \\
\hline 51 & 0.269 & 0.89 \\
\hline 52 & 0.269 & 0.688 \\
\hline 53 & 0.747 & 1 \\
\hline 54 & 0.253 & 0.944 \\
\hline 55 & 0.545 & 0.956 \\
\hline 56 & 0.515 & 0.944 \\
\hline 57 & 0.269 & 0.586 \\
\hline 58 & 0.656 & 0.956 \\
\hline 59 & 0.368 & 0.865 \\
\hline 60 & 0.415 & 0.88 \\
\hline 61 & 0.427 & 0.576 \\
\hline 62 & 0.488 & 0.816 \\
\hline 63 & 0.507 & 0.875 \\
\hline 64 & 0 & 0.928 \\
\hline 65 & 0.485 & 0.944 \\
\hline 66 & 0.432 & 0.928 \\
\hline 67 & 0.269 & 0.865 \\
\hline 68 & 0.263 & 0.956 \\
\hline 69 & 0.455 & 1 \\
\hline 70 & 0.263 & 0.944 \\
\hline 71 & 0.585 & 0.628 \\
\hline 72 & 0.656 & 0.928 \\
\hline 73 & 0 & 0.793 \\
\hline 74 & 0.493 & 0.865 \\
\hline 75 & 0.485 & 0.865 \\
\hline 76 & 0.485 & 0.586 \\
\hline 77 & 0.485 & 0.54 \\
\hline 78 & 0.348 & 0.956 \\
\hline 79 & 0.368 & 0.88 \\
\hline 80 & 0.368 & 0.928 \\
\hline 81 & 0.253 & 0.956 \\
\hline 82 & 0.415 & 0.576 \\
\hline 83 & 0.565 & 1 \\
\hline 84 & 0.355 & 0.956 \\
\hline 85 & 0.493 & 0.944 \\
\hline 86 & 0.269 & 0.576 \\
\hline 87 & 0.488 & 0.875 \\
\hline 88 & 0.355 & 0.928 \\
\hline 89 & 0.344 & 0.944 \\
\hline 90 & 0.253 & 0.928 \\
\hline 91 & 0.435 & 0.956 \\
\hline 92 & 0.269 & 0.617 \\
\hline & & \\
\hline
\end{tabular}

\begin{tabular}{|c|c|c|}
\hline Sample & FLR & FBR \\
\hline 93 & 0.355 & 0.88 \\
\hline 94 & 0.515 & 0.928 \\
\hline 95 & 0.355 & 0.944 \\
\hline 96 & 0.253 & 1 \\
\hline 97 & 0.427 & 0.956 \\
\hline 98 & 0.263 & 0.89 \\
\hline 99 & 0.253 & 0.865 \\
\hline 100 & 0.645 & 0.842 \\
\hline 101 & 0.435 & 0.833 \\
\hline 102 & 0.512 & 0.928 \\
\hline 103 & 0 & 0.956 \\
\hline 104 & 0.355 & 0.956 \\
\hline 105 & 0.747 & 0.88 \\
\hline 106 & 0.348 & 0.956 \\
\hline 107 & 0.269 & 1 \\
\hline 108 & 0.355 & 0.875 \\
\hline 109 & 0.368 & 1 \\
\hline 110 & 0.507 & 0.865 \\
\hline 111 & 0 & 0.944 \\
\hline 112 & 0.585 & 0.865 \\
\hline 113 & 0.573 & 0.793 \\
\hline 114 & 0.348 & 0.816 \\
\hline 115 & 0.507 & 0.944 \\
\hline 116 & 0.348 & 0.88 \\
\hline 117 & 0.435 & 0.928 \\
\hline 118 & 0.585 & 0.956 \\
\hline 119 & 0 & 0.89 \\
\hline 120 & 0.432 & 0.89 \\
\hline 121 & 0.355 & 0.88 \\
\hline 122 & 0.348 & 0.956 \\
\hline 123 & 0.573 & 0.928 \\
\hline 124 & 0.573 & 0.928 \\
\hline 125 & 0.415 & 1 \\
\hline 126 & 0.368 & 0.617 \\
\hline 127 & 0.737 & 0.928 \\
\hline 128 & 0.507 & 0.865 \\
\hline 129 & 0.656 & 0.89 \\
\hline 130 & 0.545 & 0.928 \\
\hline 131 & 0.263 & 0.928 \\
\hline 132 & 0.507 & 1 \\
\hline 133 & 0.435 & 0.561 \\
\hline 134 & 0.455 & 0.928 \\
\hline 135 & 0.488 & 0.944 \\
\hline 136 & 0 & 1 \\
\hline 137 & 0.435 & 1 \\
\hline
\end{tabular}




\section{$G_{p}$ Results}

\begin{tabular}{|c|c|c|}
\hline Sample & FLR & FBR \\
\hline 138 & \begin{tabular}{|l|}
1 \\
\end{tabular} & \begin{tabular}{|l|}
0.51 \\
\end{tabular} \\
\hline 139 & 0.731 & 0.45 \\
\hline 140 & 0.565 & 0.563 \\
\hline 141 & 0.545 & 0.59 \\
\hline 142 & 1 & 0.563 \\
\hline 143 & 0.485 & 0.674 \\
\hline 144 & 0.632 & 0.776 \\
\hline 145 & 1 & 0.401 \\
\hline 146 & 0.493 & 0.638 \\
\hline 147 & 0.747 & 0.331 \\
\hline 148 & 0.545 & 0.499 \\
\hline 149 & 1 & 0.373 \\
\hline 150 & 0.493 & 0.59 \\
\hline 151 & 0.731 & 0.564 \\
\hline 152 & 0.737 & 0.403 \\
\hline 153 & 1 & 0.408 \\
\hline 154 & 1 & 0.488 \\
\hline 155 & 1 & 0.611 \\
\hline 156 & 0.565 & 0.324 \\
\hline 157 & 0.573 & 0.563 \\
\hline 158 & 0.632 & 0.475 \\
\hline 159 & 0.731 & 0.728 \\
\hline 160 & 1 & 0.466 \\
\hline 161 & 0.568 & 0.538 \\
\hline 162 & 1 & 0.403 \\
\hline 163 & 0.632 & 0.604 \\
\hline 164 & 0.545 & 0.654 \\
\hline 165 & 1 & 0.674 \\
\hline 166 & 0.632 & 0.663 \\
\hline 167 & 0.545 & 0.364 \\
\hline 168 & 0.415 & 0.654 \\
\hline 169 & 0.731 & 0.785 \\
\hline 170 & 0.415 & 0.735 \\
\hline 171 & 0.545 & 0.604 \\
\hline 172 & 1 & 0.553 \\
\hline 173 & 0.568 & 0.381 \\
\hline 174 & 0.545 & 0.51 \\
\hline 175 & 1 & 0.487 \\
\hline 176 & 0.348 & 0.51 \\
\hline 177 & 0.488 & 0.549 \\
\hline 178 & 0.747 & 0.663 \\
\hline 179 & 0.493 & 0.564 \\
\hline 180 & 0.568 & 0.563 \\
\hline 181 & 0.488 & 0.373 \\
\hline 182 & 0.632 & 0.443 \\
\hline 183 & 0.731 & 0.563 \\
\hline 184 & 1 & 0.53 \\
\hline 185 & 0.737 & 0.757 \\
\hline 186 & 0.632 & 0.403 \\
\hline 187 & 0.632 & 0.59 \\
\hline 188 & 0.568 & 0.844 \\
\hline 189 & 0.415 & 0.266 \\
\hline 190 & 1 & 0.498 \\
\hline 191 & 1 & 0.364 \\
\hline 192 & 1 & 0.364 \\
\hline 193 & 1 & 0.45 \\
\hline 194 & 0.415 & 0.51 \\
\hline 195 & 0.545 & 0.705 \\
\hline 196 & 0.568 & 0.475 \\
\hline 197 & 0.737 & 0.617 \\
\hline 198 & 1 & 0.771 \\
\hline 199 & 0.737 & 0.403 \\
\hline
\end{tabular}

\begin{tabular}{|c|c|c|}
\hline Sample & FLR & FBR \\
\hline 200 & 1 & \begin{tabular}{|l|}
0.512 \\
\end{tabular} \\
\hline 201 & 1 & 0.654 \\
\hline 202 & 0.415 & 0.53 \\
\hline 203 & 1 & 0.84 \\
\hline 204 & 0.545 & 0.55 \\
\hline 205 & 0.747 & 0.563 \\
\hline 206 & 0.348 & 0.731 \\
\hline 207 & 0.731 & 0.572 \\
\hline 208 & 0.545 & 0.619 \\
\hline 209 & 0.632 & 0.604 \\
\hline 210 & 0.488 & 0.51 \\
\hline 211 & 0.545 & 0.403 \\
\hline 212 & 1 & 0.705 \\
\hline 213 & 0.737 & 0.475 \\
\hline 214 & 0.415 & 0.51 \\
\hline 215 & 1 & 0.842 \\
\hline 216 & 1 & 0.604 \\
\hline 217 & 0.731 & 0.544 \\
\hline 218 & 0.737 & 0.619 \\
\hline 219 & 1 & 0.45 \\
\hline 220 & 0.632 & 0.604 \\
\hline 221 & 1 & 0.53 \\
\hline 222 & 0.568 & 0.585 \\
\hline 223 & 1 & 0.629 \\
\hline 224 & 0.545 & 0.757 \\
\hline 225 & 0.545 & 0.735 \\
\hline 226 & 1 & 0.674 \\
\hline 227 & 0.737 & 0.553 \\
\hline 228 & 0.656 & 0.401 \\
\hline 229 & 1 & 0.364 \\
\hline 230 & 0.545 & 0.45 \\
\hline 231 & 0.737 & 0.51 \\
\hline 232 & 0.545 & 0.654 \\
\hline 233 & 0.545 & 0.373 \\
\hline 234 & 0.545 & 0.53 \\
\hline 235 & 1 & 0.59 \\
\hline 236 & 0.632 & 0.757 \\
\hline 237 & 0.545 & 0.799 \\
\hline 238 & 0.632 & 0.604 \\
\hline 239 & 0.652 & 0.525 \\
\hline 240 & 0.488 & 0.498 \\
\hline 241 & 0.545 & 0.401 \\
\hline 242 & 0.632 & 0.354 \\
\hline 243 & 0.737 & 0.585 \\
\hline 244 & 0.493 & 0.488 \\
\hline 245 & 1 & 0.499 \\
\hline 246 & 1 & 0.729 \\
\hline 247 & 0.632 & 0.585 \\
\hline 248 & 0.348 & 0.674 \\
\hline 249 & 0.512 & 0.51 \\
\hline 250 & 0.632 & 0.705 \\
\hline 251 & 0.747 & 0.757 \\
\hline 252 & 1 & 0.663 \\
\hline 253 & 0.737 & 0.525 \\
\hline 254 & 1 & 0.629 \\
\hline 255 & 0.545 & 0.815 \\
\hline 256 & 0.568 & 0.499 \\
\hline 257 & 1 & 0.563 \\
\hline 258 & 0.632 & 0.654 \\
\hline 259 & 0.545 & 0.557 \\
\hline 260 & 0.747 & 0.875 \\
\hline 261 & 0.737 & 0.519 \\
\hline
\end{tabular}

\begin{tabular}{|c|c|c|}
\hline Sample & FLR & FBR \\
\hline 262 & 0.545 & 0.72 \\
\hline 263 & 0.348 & 0.663 \\
\hline 264 & 1 & 0.498 \\
\hline 265 & 0.545 & 0.55 \\
\hline 266 & 0.545 & 0.735 \\
\hline 267 & 1 & 0.488 \\
\hline 268 & 0.355 & 0.896 \\
\hline 269 & 0.545 & 0.635 \\
\hline 270 & 1 & 0.403 \\
\hline 271 & 0.493 & 0.776 \\
\hline 272 & 1 & 0.45 \\
\hline 273 & 0.545 & 0.45 \\
\hline 274 & 0.348 & 0.51 \\
\hline 275 & 0.737 & 0.572 \\
\hline 276 & 1 & 0.663 \\
\hline 277 & 1 & 0.714 \\
\hline 278 & 0.731 & 0.498 \\
\hline 279 & 0.632 & 0.915 \\
\hline 280 & 0.632 & 0.638 \\
\hline 281 & 0.568 & 0.601 \\
\hline 282 & 0.348 & 0.59 \\
\hline 283 & 1 & 0.475 \\
\hline 284 & 0.493 & 0.364 \\
\hline 285 & 0.348 & 0.566 \\
\hline 286 & 0.632 & 0.629 \\
\hline 287 & 1 & 0.67 \\
\hline 288 & 1 & 0.731 \\
\hline 289 & 0.573 & 0.572 \\
\hline 290 & 0.632 & 0.617 \\
\hline 291 & 0.348 & 0.498 \\
\hline 292 & 1 & 0.412 \\
\hline 293 & 0.488 & 0.604 \\
\hline 294 & 0.488 & 0.51 \\
\hline 295 & 0.632 & 0.53 \\
\hline 296 & 0.545 & 0.475 \\
\hline 297 & 0.645 & 0.638 \\
\hline 298 & 0.427 & 0.55 \\
\hline 299 & 0.253 & 0.51 \\
\hline 300 & 1 & 0.674 \\
\hline 301 & 0.737 & 0.585 \\
\hline 302 & 0.545 & 0.53 \\
\hline 303 & 0.632 & 0.776 \\
\hline 304 & 0.731 & 0.705 \\
\hline 305 & 0.632 & 0.345 \\
\hline 306 & 0.545 & 0.549 \\
\hline 307 & 1 & 0.519 \\
\hline 308 & 1 & 0.544 \\
\hline 309 & 1 & 0.475 \\
\hline 310 & 0.545 & 0.53 \\
\hline 311 & 0.632 & 0.714 \\
\hline 312 & 0.263 & 0.45 \\
\hline 313 & 0.545 & 0.654 \\
\hline 314 & 0.632 & 0.354 \\
\hline 315 & 0.545 & 0.705 \\
\hline 316 & 0.632 & 0.563 \\
\hline 317 & 0.568 & 0.45 \\
\hline 318 & 1 & 0.525 \\
\hline 319 & 0.656 & 0.728 \\
\hline 320 & 0.747 & 0.519 \\
\hline 321 & 0.415 & 0.629 \\
\hline 322 & 0.731 & 0.53 \\
\hline 323 & 0.415 & 0.553 \\
\hline
\end{tabular}




\begin{tabular}{|c|c|c|}
\hline Sample & FLR & FBR \\
\hline 324 & 1 & 0.401 \\
\hline 325 & 0.632 & 0.45 \\
\hline 326 & 1 & 0.661 \\
\hline 327 & 0.355 & 0.76 \\
\hline 328 & 1 & 0.757 \\
\hline 329 & 0.731 & 0.45 \\
\hline 330 & 1 & 0.629 \\
\hline 331 & 0.632 & 0.557 \\
\hline 332 & 1 & 0.654 \\
\hline 333 & 1 & 0.53 \\
\hline 334 & 0.731 & 0.364 \\
\hline 335 & 1 & 0.55 \\
\hline 336 & 0.747 & 0.498 \\
\hline 337 & 1 & 0.525 \\
\hline 338 & 1 & 0.844 \\
\hline 339 & 1 & 0.59 \\
\hline 340 & 0.545 & 0.475 \\
\hline 341 & 0.731 & 0.454 \\
\hline 342 & 0.415 & 0.776 \\
\hline 343 & 0.545 & 0.563 \\
\hline 344 & 0.415 & 0.354 \\
\hline 345 & 0.348 & 0.757 \\
\hline 346 & 0.545 & 0.53 \\
\hline 347 & 0.632 & 0.604 \\
\hline 348 & 0.493 & 0.512 \\
\hline 349 & 0.632 & 0.563 \\
\hline 350 & 0.565 & 0.537 \\
\hline 351 & 0.515 & 0.814 \\
\hline 352 & 0.573 & 0.498 \\
\hline 353 & 1 & 0.661 \\
\hline 354 & 0.545 & 0.814 \\
\hline 355 & 0.545 & 0.519 \\
\hline 356 & 0.415 & 0.553 \\
\hline 357 & 0.415 & 0.785 \\
\hline 358 & 0.415 & 0.585 \\
\hline 359 & 0.565 & 0.324 \\
\hline 360 & 0.737 & 0.549 \\
\hline 361 & 1 & 0.705 \\
\hline 362 & 0.545 & 0.735 \\
\hline 363 & 0.632 & 0.896 \\
\hline 364 & 1 & 0.399 \\
\hline 365 & 0.545 & 0.59 \\
\hline 366 & 0.568 & 0.525 \\
\hline 367 & 0.344 & 0.553 \\
\hline 368 & 0.432 & 0.757 \\
\hline 369 & 1 & 0.776 \\
\hline 370 & 1 & 0.67 \\
\hline 371 & 1 & 0.59 \\
\hline 372 & 0.632 & 0.364 \\
\hline 373 & 0.415 & 0.585 \\
\hline 374 & 0.632 & 0.564 \\
\hline 375 & 1 & 0.84 \\
\hline 376 & 0.585 & 0.766 \\
\hline 377 & 0.568 & 0.488 \\
\hline 378 & 0.632 & 0.354 \\
\hline 379 & 0.485 & 0.354 \\
\hline 380 & 0.737 & 0.55 \\
\hline 381 & 0.545 & 0.512 \\
\hline 382 & 0.485 & 0.55 \\
\hline 383 & 1 & 0.714 \\
\hline 384 & 1 & 0.663 \\
\hline 385 & 0.632 & 0.714 \\
\hline & & \\
\hline
\end{tabular}

\begin{tabular}{|c|c|c|}
\hline Sample & FLR & FBR \\
\hline 386 & 0.545 & 0.714 \\
\hline 387 & 0.731 & 0.412 \\
\hline 388 & 0.493 & 0.776 \\
\hline 389 & 1 & 0.691 \\
\hline 390 & 0.632 & 0.735 \\
\hline 391 & 0.632 & 0.525 \\
\hline 392 & 0.415 & 0.557 \\
\hline 393 & 0.545 & 0.499 \\
\hline 394 & 0.545 & 0.617 \\
\hline 395 & 1 & 0.53 \\
\hline 396 & 0.632 & 0.674 \\
\hline 397 & 1 & 0.629 \\
\hline 398 & 0.632 & 0.604 \\
\hline 399 & 1 & 0.563 \\
\hline 400 & 1 & 0.51 \\
\hline 401 & 0.415 & 0.785 \\
\hline 402 & 0.415 & 0.572 \\
\hline 403 & 0.545 & 0.454 \\
\hline 404 & 0.485 & 0.657 \\
\hline 405 & 0.485 & 0.705 \\
\hline 406 & 1 & 0.51 \\
\hline 407 & 1 & 0.381 \\
\hline 408 & 1 & 0.45 \\
\hline 409 & 0.632 & 0.629 \\
\hline 410 & 0.573 & 0.51 \\
\hline 411 & 0.545 & 0.55 \\
\hline 412 & 1 & 0.488 \\
\hline 413 & 1 & 0.519 \\
\hline 414 & 1 & 0.47 \\
\hline 415 & 1 & 0.638 \\
\hline 416 & 0.632 & 0.51 \\
\hline 417 & 0.731 & 0.824 \\
\hline 418 & 1 & 0.475 \\
\hline 419 & 0.573 & 0.452 \\
\hline 420 & 0.415 & 0.538 \\
\hline 421 & 0.485 & 0.757 \\
\hline 422 & 1 & 0.604 \\
\hline 423 & 0.545 & 0.59 \\
\hline 424 & 0.747 & 0.859 \\
\hline 425 & 0.355 & 0.538 \\
\hline 426 & 0.545 & 0.585 \\
\hline 427 & 0.493 & 0.415 \\
\hline 428 & 1 & 0.674 \\
\hline 429 & 0.545 & 0.674 \\
\hline 430 & 0.348 & 0.525 \\
\hline 431 & 0.737 & 0.572 \\
\hline 432 & 0.731 & 0.483 \\
\hline 433 & 0.731 & 0.617 \\
\hline 434 & 0.488 & 0.766 \\
\hline 435 & 1 & 0.553 \\
\hline 436 & 0.747 & 0.896 \\
\hline 437 & 0.545 & 0.51 \\
\hline 438 & 0.737 & 0.585 \\
\hline 439 & 0.415 & 0.539 \\
\hline 440 & 0.632 & 0.799 \\
\hline 441 & 0.545 & 0.553 \\
\hline 442 & 0.415 & 0.781 \\
\hline 443 & 0.545 & 0.654 \\
\hline 444 & 1 & 0.604 \\
\hline 445 & 0.731 & 0.324 \\
\hline 446 & 0.573 & 0.815 \\
\hline 447 & 0.632 & 0.617 \\
\hline & & \\
\hline
\end{tabular}

\begin{tabular}{|c|c|c|}
\hline Sample & FLR & FBR \\
\hline 448 & 0.545 & 0.714 \\
\hline 449 & 0.545 & 0.538 \\
\hline 450 & 0.645 & 0.525 \\
\hline 451 & 0.488 & 0.638 \\
\hline 452 & 0.493 & 0.48 \\
\hline 453 & 0.415 & 0.705 \\
\hline 454 & 1 & 0.814 \\
\hline 455 & 0.632 & 0.714 \\
\hline 456 & 0.573 & 0.488 \\
\hline 457 & 0.545 & 0.585 \\
\hline 458 & 0.573 & 0.535 \\
\hline 459 & 0.415 & 0.45 \\
\hline 460 & 0.747 & 0.53 \\
\hline 461 & 1 & 0.563 \\
\hline 462 & 1 & 0.617 \\
\hline 463 & 0.507 & 0.549 \\
\hline 464 & 0.415 & 0.549 \\
\hline 465 & 0.355 & 0.373 \\
\hline 466 & 0.573 & 0.757 \\
\hline 467 & 0.737 & 0.563 \\
\hline 468 & 1 & 0.51 \\
\hline 469 & 0.545 & 0.604 \\
\hline 470 & 0.565 & 0.525 \\
\hline 471 & 0.415 & 0.324 \\
\hline 472 & 1 & 0.572 \\
\hline 473 & 0.573 & 0.563 \\
\hline 474 & 0.488 & 0.59 \\
\hline 475 & 0.573 & 0.619 \\
\hline 476 & 0.415 & 0.728 \\
\hline 477 & 0.415 & 0.364 \\
\hline 478 & 0.253 & 0.537 \\
\hline 479 & 1 & 0.348 \\
\hline 480 & 0.568 & 0.563 \\
\hline 481 & 0.545 & 0.549 \\
\hline 482 & 0.348 & 0.674 \\
\hline 483 & 1 & 0.163 \\
\hline 484 & 0.355 & 0.52 \\
\hline 485 & 1 & 0.401 \\
\hline 486 & 0.632 & 0.785 \\
\hline 487 & 1 & 0.757 \\
\hline 488 & 0.568 & 0.705 \\
\hline 489 & 0.731 & 0.331 \\
\hline 490 & 1 & 0.824 \\
\hline 491 & 0.731 & 0.487 \\
\hline 492 & 1 & 0.51 \\
\hline 493 & 0.545 & 0.757 \\
\hline 494 & 1 & 0.814 \\
\hline 495 & 0.632 & 0.553 \\
\hline 496 & 1 & 0.45 \\
\hline 497 & 0.737 & 0.177 \\
\hline 498 & 0.415 & 0.403 \\
\hline 499 & 0.632 & 0.525 \\
\hline 500 & 1 & 0.728 \\
\hline 501 & 0.545 & 0.657 \\
\hline 502 & 0.737 & 0.735 \\
\hline 503 & 0.545 & 0.629 \\
\hline 504 & 0.731 & 0.563 \\
\hline 505 & 0.545 & 0.604 \\
\hline 506 & 0.737 & 0.308 \\
\hline 507 & 0.415 & 0.785 \\
\hline 508 & 0.545 & 0.705 \\
\hline 509 & 0.269 & 0.59 \\
\hline & & \\
\hline
\end{tabular}




\section{Coding (With corresponding images)}

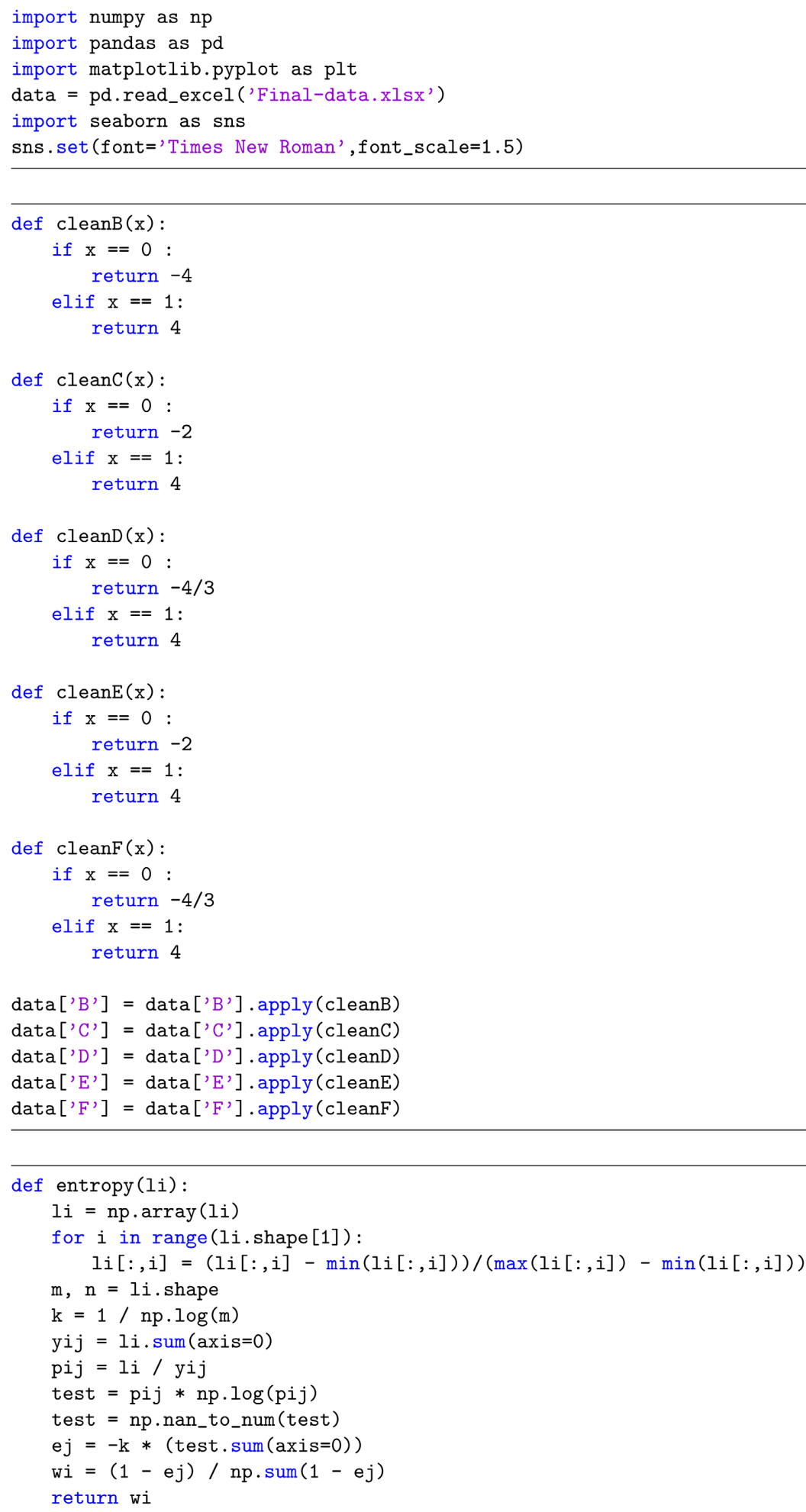




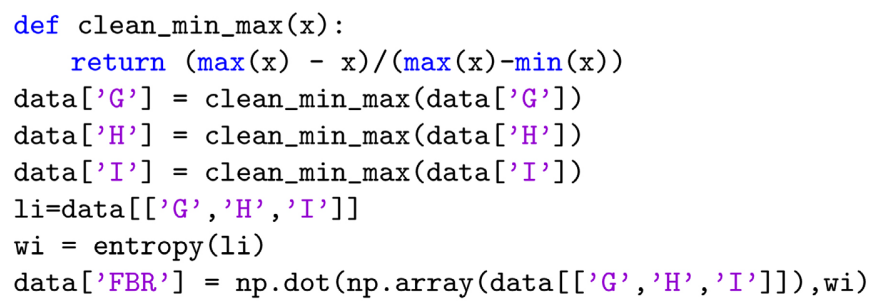



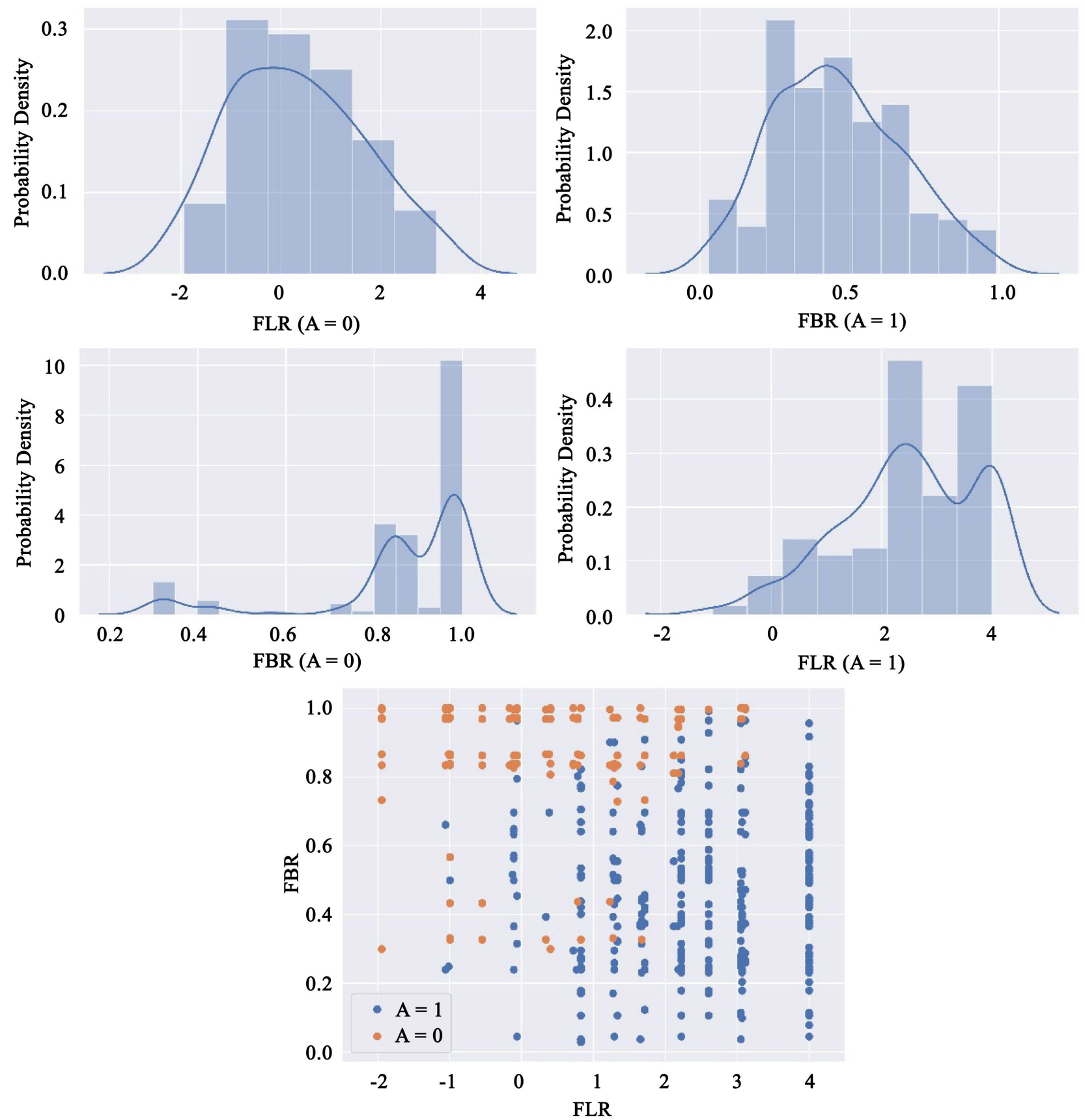